stance, all kinds of cooking-pots and other arrangements for cooking would belong to one class. The mere fact that certain pots are made of clay would not justify the establishment of a pottery department. This quality of being made of clay is incidental, and does not agree with the psychological basis.

There is one point of view which justifies a classification according to inventions in a psychological museum. This is the extent to which each invention is used by a people: for instance, in what branches of life pottery is made use of, which may be limited in one tribe, very wide in another. But in this case the purpose of the object will not be the principle of division, but the principal invention applied in its manufacture; and thus the specimens would not be arranged according to Professor Mason's system, objects serving widely differing purposes belonging to one class. Therefore I cannot consider it justifiable to make technology, in the sense Professor Mason does, the basis of arranging ethnological collections.

One reason ought to make us very cautious in applying the argument from analogy in ethnology as well as in other sciences of similar character ; biology, for instance. Former events, as I have already said, leave their stamp on the present character of a people. I consider it one of the greatest achievements of Darwinism to have brought to light this fact, and thus to have made a physical treatment of biology and psychology possible. The fact may be expressed by the words, "the physiological and psychological state of an organism at a certain moment is a function of its whole history;" that is, the character and future development of a biological or ethnological phenomenon is not expressed by its appearance, by the state in which it $i s$, but by its whole history. Physicists will understand the important meaning of this fact. The outward appearance of two phenomena may be identical, yet their immanent qualities may be altogether different: therefore arguments from analogies of the outward appearance, such as shown in Professor Mason's collections, are deceptive. These remarks show how the same phenomena may originate from unlike causes, and that my opinion does not at all strive against the axiom, 'Like effects spring from like causes,' which belongs to that class of axioms which cannot be converted. Though like causes have like effects, like effects have not like causes.

From my statement it will be understood that I cannot content myself with Mr. Dall's remark, in the letter contained in to-day's issue, that both standpoints contain part of the truth. I have expressed in another place (Verh. Ges. für Erdkunde, Berlin, 1886 , No.7) my opinion on Dall's ethnological method, and emphasized, as I have here also, the necessity of studying each ethnological phenomenon individually.

In conclusion I have to add a few words on the practical side of the question upon which Professor Mason and Mr. Dall touch. In regard to this question, I concur with Mr. Dall, and believe that the public will be much more benefited by the tribal arrangement of ethnological collections.

I cannot agree with Professor Mason's proposal of arranging the cases like a checker-board. In ethnology all is individuality. We should be compelled to leave long rows of cases empty, as certain phe- nomena occur but in very few tribes. It would be almost impossible to show in this way all important ethnological phenomena, the historical development of tribes, the influence of neighbors and surroundings, etc. It is my opinion that the main object of ethnological collections should be the dissemination of the fact that civilization is not something absolute, but that it is relative, and that our ideas and conceptions are true only so far as our civilization goes. I believe that this object can be accomplished only by the tribal arrangement of collections. The second object, which is subordinate to the other, is to show how far each and every civilization is the outcome of its geographical and historica! surroundings. Here the line of tribal arrangement may sometimes be broken, in order to show an historical series of specimens; but I consider this latter point of view subordinate to the former, and should choose to arrange collections of duplicates for illustrating those ideas, as it were, as an explanation of the facts contained in the tribal series. Of course, it is generally impossible to do this, on account of the lack of specimens, or, more frequently, on account of the lack of our knowledge ; but it is my ideal of an ethnological museum. I wish to state here again that I am not at all opposed to Mantegazza's psychological museum, which will be very suggestive and important for the development of science, but I consider the ethnological museum indispensable for controlling the ideas suggested by the analogies shown in the psychological collection, and as the only means of showing the state of culture of man.

Dr. Franz Boas.

\section{Correlation of the geological structure of the maritime province of Canada with that of western Europe.}

I take the liberty to send a corrected abstract of a paper read by me before the Royal society of Canada, and which may perhaps be of interest to some of your readers : -

As early as 1855, in the first edition of 'Acadian geology, the author had indicated the close resemblance in structure and mineral productions of Nova Scotia and New Brunswick with the British Islands, and in subsequent editions of the same work further illustrations were given of this fact. Recent researches by Bailey, Matthew, Fletcher, Ells, and others, had still more distinctively indicated this resemblance, as well as the distinctness of the maritime geology from that of the great interior plateau of Canada and the United States. In short, as argued by the author in his recent address before the British association, the geology of the Atlantic margins of America and Europe is substantially the same, and distinct from that found west of the Appalachians in America and in central and eastern Europe. In this fact has originated much of the difficulty experienced in correlating the geological formations of eastern Canada with those of Ontario, of New York and Ohio, as well as similar difficulties in Europe which have led to much controversy and difference of classification and nomenclature. One object of the present communication was to show that the system of classification of paleozoic sediments employed for the interior plateau of the American continent requires very important modifications when applied to the Atlantic coast, and that neglect of this has led to serious misconceptions. 
The rugged islands of Laurentian and Huronian rocks correspond in both regions, and show an identity of succession in deposits as well as a synchronism of the great folds and lateral pressures which have disturbed these old formations on both sides of the Atlantic. The Cambrian sediments and fossils as originally described by Hartt, and more recently and in so great detail by Matthew, are in close correspondence with those of Wales, and not identical with those of internal America. The recent paper of Lapworth on the graptolites affords evidence of the same kind, and shows that these were Atlantic animals in their time. It also throws much additional light on the Quebec group of Logan, considered as an Atlantic marginal formation, representing a great lapse of time in the Cambrian and Ordovician periods. The author had long ago shown that the Siluro-Cambrian or Ordovician of Nova Scotia conformed more nearly to that of Cumberland and Wales than to the great limestone formations of Quebec, Ontario, and New York. The upper Silurian also is of the type of that of England and Wales, - a fact very marked in its fossil remains as well as in its sediments.

The parallelism in the Erian or Devonian in both countries is most marked, both in rocks and fossils ; and, while this is apparent in the fishes as worked up by Mr. Whiteaves, it is no less manifest in the fossil plants as described by the author.

The carboniferous, in its limited troughs, the character of its beds, and its fossil animals and plants, also points to a closer relationship in that period between the two shores of the Atlantic than between the Atlantic coast and the inland area. This was evidenced by comparative lists of species.

The trias of Nova Scotia and of Prince Edward Island, as the author had shown in 1868 (Journ. geol. soc. Lond.), resembles that of England very closely in its aqueous deposits and in its associated trappean rocks.

Beyond this, the geology of the maritime provinces presents no materials for comparison till we arrive at the bowlder drift and other pleistocene deposits. In regard to these, without entering into disputed questions any further than to say that the observations of the author, as well as those more recently made by Mr. Chalmers, conclusively proved that submergence and local ice-drift were dominant as causes of distribution of bowlders and other material, there was evidence of great similarity. The marine beds described by Mr. Matthew at St. John were precise equivalents of the Clyde beds of Scotland, as were the upper shell-bearing beds of Prince Edward Island and Bay de Chaleur of those in Aberdeenshire and other parts of Scotland, and the Uddevalla beds of Sweden. The bowlders drifted from Labrador to Nova Scotia were the representatives of those in Europe scattered southward from Scandinavia, and the local drift in various directions from the hills was the counterpart of that observed in Great Britain. The survival of Mastodon giganteus in Cape Breton, to the close of the pleistocene, is a decided American feature, and so is the absence of any evidence of pleistocene man.

The conclusion of the author was, that, in so far as paleontology and the subdivisions of systems of formations are concerned, the geology of the maritime provinces is European, or perhaps more properly Atlantic, rather than American, and is to be correlated rather with the British Islands and Scan- dinavia than with interior Canada and the United States. The latter country, even on its eastern coast, possesses a much less perfect representation of these Atlantic deposits than that in the maritime provinces and Newfoundland; though the recent studies of Crosby, Dale, and others are developing new points of this kind in the geology of New England, and Hitchcock and others have shown that the New Brunswick geology extends into Maine.

The paper further discussed the bearing of these facts on the successive stages of the physical geography of eastern America in the Cambrian, Silurian, Erian, carboniferous, and triassic records.

J. WM. Dawson.

Montreal, May 30.

\section{Sea-sickness.}

In Science for June 3, I find a very interesting review of the medical literature of this subject. It is but natural that means, both prophylactic and curative, should be sought for the benefit of those who find a sea-voyage one of torment rather than pleasure; and the writer has frequently thought that some suggestions derived from the otologist's experience might not be without interest in, this connection. Thus, in a considerable experience among persons suffering from aural disease, it has been found that vertiginous symptoms are of frequent occurrence; that the phenomena, in fact, which constitute what is known as 'sea-sickness,' are by no means exclusively experienced by the comparatively few who submit to being tossed about at sea. Indeed, as every on $\theta$ familiar with the subject very well knows, most of the symptoms going to make up this malady are found, in some form or other, to render the lives of a great many persons living upon terra firma most miserable. A great many of these individuals experience almost daily, frequently much oftener, seasickness without ever going on board ship. The sufferings of these seem to be owing to a faulty condition of the transmitting mechanism of the ear,- defects in respect to which it may be said, that, when normal tension of this portion of the hearing-organ is thus wanting, nearly all the symptoms of sea-sickness may take place from slight though altogether unavoidable, constantly occurring causes. Persons thus affected cannot rise up suddenly from a recumbent position, or otherwise change the pose of the head, without feeling dizzy or staggering when attempting locomotion. Sometimes they experience nausea, and feel faint and otherwise miserable. Or the mere acts of swallowing, yawning, or hiccoughing, whereby intra-tympanal aeration is suddenly altered, may be followed by distressing and sometimes alarming symptoms. The experience of vertiginous phenomena in some form or other, closely simulating what is known as 'sea-sickness,' likewise occurs to the aurally defective in consequence of cerebral concussion caused by impacts of the stapes upon the fluid in the labyrinth, and arising from oscillatory movements of the drum-head when its functions are no longer under the dominance of normal tension. The erratic drum-head, flapping in response to sudden movements of the head, acts of swallowing, etc., would seem to force the stapes into and out of the oval window to an extent far exceeding its physiological limits; and, thus jostled about, the stapes, with each excursion of the drumhead, imparts a shock to the labyrinthine fluid. I am aware that it has long been held by physiologists 